\title{
Cognitive regeneration or enhancement: the ethical issues
}

\section{Sarah Chan \& Jdm Harisłt}

${ }^{\dagger}$ Author for correspondence ${ }^{1}$ Research Fellow Centre for Social Ethics and Policy, University of $M$ anchester, Williamson Building 2.07, U K ${ }^{2}$ Sir D avid Alliance Professor of Bioethics Institute of $M$ edicine Law and Bioethics School of Law U niversity of $M$ anchester 0 xford Road $M$ anchester M 13 9PL, UK Tel.: +44 161275 3473; Fax: +44 1612757704
Keywords cognitive enhancement, ethics, regeneration

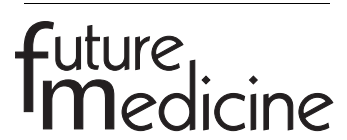

The neurological and physiological basis of brain function and disease has been a significant focus of investigation throughout the history of medical research. Recent advances in understanding have led to the development of new treatments for diseases of the brain and defects of cognitive and behavioral function: pharmacological, cell-based and even gene therapy may all provide keys to cognitive regeneration. Such therapies, however, might be applied not only towards restoring brain function in the case of disease but to enhance cognitive function for healthy individuals. The concept of cognitive enhancement raises many ethical issues: whether brain-enhancing treatments should be developed and made available and to whom; and what potential consequences might arise? This paper explores some of the ethical arguments associated with cognitive enhancement and concludes that although the technology involved is as yet uncertain and issues of social equity remain to be addressed, the potential benefit of enhancing human brain function is clear.

"The brain is an organ of minor importance". Thus stated Aristotle in the 4th century BC [1]. Today, almost two and a half millennia later, the brain is regarded as one of the body's most vital organs, and the organ most integral to our conception of selfhood. We understand the brain as the physical locus of thoughts, awareness, emotions and desires - in short the seat of personality; while brain-death is considered in many ways equivalent to the death of the person as an individual, extinguishing certain legal and possibly moral rights.

Advances in medical science have brought us closer to understanding the pathophysiology of many disorders of the brain. Parkinson's disease, for example, is caused by the degeneration of dopaminergic neurons, first resulting in motor defects and later depression and dementia [2]. Alzheimer's disease, involving memory loss, dementia and impairment of cognitive function, results mainly from neurodegeneration caused by the accumulation of protein plaques in the brain. 0 ur knowledge of the neurophysiological basis of behavior is also expanding: conditions such as schizophrenia, attention-deficit hyperactivity disorder (ADHD) and depression are known to involve disruptions in brain neurochemistry. However, although the primary pathology of these diseases may be known, the complex interactions between neurochemistry, cerebral pathology and brain function mean that the underlying causes for these and most other brain disorders are yet to be fully characterized.
$\mathrm{H}$ istorically, the development of treatments for pathological brain functioning has progressed in an experimental, sometimes haphazard manner. Therapies such as inducing fever through malaria infection to treat palsy and electroconvulsive shock treatment for depression, pioneered early last century, proved to have some degree of efficacy but also occasionally resulted in unwanted side-effects - four of the ten patients in the first malaria trial died as a result of the treatment [3]. Modern pharmacological interventions such as psychotropic and neurotropic drugs have greater specificity of action, but the full spectrum of effects of such drugs on the brain is often still unclear.

Regenerative medicine is already beginning to suggest great potential for the treatment and prevention of brain disorders. N eurodegenerative diseases may be reversed or slowed by interventions that promote neuronal repair: for example, current stem cell research promises the potential to provide cures for Parkinson's and Alzheimer's disease [4]. The relatively new field of molecular genetics holds further possibilities for modification of brain activity. M any cognitive and behavioral traits are associated with a genetic component; mental and behavioral disorders such as schizophrenia [5], bipolar disorder and ADHD [6] as well as some mental abilities (for example intelligence $[7,8]$ and musical absolute pitch [9]) are now thought to have some genetic basis. The identification of 
specific genes involved in such conditions could allow the development of better-targeted treatments, selection against disorders or for beneficial characteristics, or even gene therapy.

The possibility of using regenerative medical therapies to treat brain disorders and our increasing ability to control and modify the functioning of the brain has raised the question of the ethics of using therapeutic interventions that may also constitute enhancements. W hat if such interventions could be applied not only as treatments, but to increase cognitive powers in normal individuals? We will look at the ethics of cognitive enhancements generally, not confining ourselves to those which are strictly speaking also regenerative, because the ethical issues are the same.

The idea of being able to boost brainpower, whether by drugs or other augmentation has long been speculated upon. Each new discovery of a gene or drug affecting intelligence, learning or memory is touted as portending a future of 'smart pills' and genetically engineered supersmart humans. These concepts have been explored in science fiction for decades, but it is highly possible that in the next decade, such inventions will move into the realm of fact. Genetic improvement of memory has been demonstrated in mice [10]; numerous drugs to improve mental performance, concentration or mood - Prozac ${ }^{T M}$, Valium $^{\circledR}$, Ritalin $^{\circledR}$ and modafinil - are already available for humans. There is even the possibility of using computer technology to integrate with and improve brain function [11].

In considering the possibility of brain enhancement, the first question to be asked is whether enhancement of mental abilities such as intelligence and memory is a good thing in itself. Certainly for a given individual, it is hard to see how a simple increase in intelligence could be other than beneficial: intelligence has been shown to correlate with socioeconomic success, health and longevity [12,13], all of which are normative goods. At the population level, a society composed of people living better individual lives would also presumably ben efit as a result of these improvements.

If increased cognitive ability is a benefit and causes no harm, are there other reasons to exercise caution in using brain-enhancing technologies? O ne obvious difficulty is that although the talk often is of enhanced intelligence, intelligence is an elusive concept, incorporating many different aspects: reasoning and analytical ability, concentration and attention span, memory, per- severance and so-called 'emotional intelligence', among others. Merely enhancing one of these characteristics may not bring the theoretical benefit that might be expected. M emory, for example, is important not only for the recall of relevant information but also because it discards irrelevant input; improving memory so that all sorts of information is retained, regardless of relevance, can interfere significantly with other cognitive functions [14].

The complexity of brain function and its effect on behavior and cognition is perhaps one factor that distinguishes neuro-enhancement from other posited physical forms of enhancement. N euroscience is, as yet, an inexact predictor of the effects of a given intervention on mental ability or behavior: an increase in neuronal proliferation or altered neurotransmitter levels will not necessarily produce an improvement in brain function.

O ne way in which this unpredictability may manifest is in the risks or side-effects associated with enhancement of brain function. Breathing air with elevated oxygen levels can heighten perception and reflexes, but also causes tissue damage. M ethylphenidate, the active drug ingredient in the ADHD treatment Ritalin, can be used to increase attention span and concentration, but reduces performance in spatial memory tests. M odafinil, developed to treat schizophrenia [15] and ADHD [16], has been hailed as having the potential to revolutionize society because its use in healthy individuals dramatically reduces the need for sleep, enabling sustained performance and greater productivity; but studies so far have failed to elucidate the mechanism by which the drug acts, and the long-term consequences of the treatment on brain neurochemistry and metabolism are still unknown [17]. The effects of any attempt to interfere with normal brain function may be similarly unpredictable.

Concerns about risk and safety of neuroenhancement should, like all such concerns, be seriously considered, but these concerns are not enough to rule out such treatments as unethical. As for all new and experimental clinical procedures, risk and benefit must be weighed in the balance to decide whether the gain is worth the potential danger incurred. If there is both significant individual and social benefit to be gained at the expense of undergoing real risk, the choice should be left to the individual, as for participation in clinical trials and research. A difficulty perhaps unique to this area of science, however, is the dearth of useful animal 
models for human cognition on which preliminary trials can be carried out. Tests on mice or similar species may show physiological effects, but cannot observe or suggest what the overall effect of such changes will be on the complex functioning of the human brain. Even tests on nonhuman primates are limited in the information they can offer as to the potential changes that might be induced in human thought and behavior; and the use of nonhuman primates is widely considered to be more ethically problematic than the use of other animals for research [18].

Alongside this note of caution we should al so acknowledge the potential Pandora's Box dangers that neuro-enhancement presents. Once released, brain-enhancing treatments are likely to be impossible to restrain. $\mathrm{H}$ aving experienced the power of artificially augmented mental faculties, who would voluntarily give up such capabilities? U sers of neurogenic drugs may suffer from lifestyle addiction to the enhanced cognitive capacities conferred by the treatments, even if the drugs are not physiologically addictive. While being made permanently smarter may be good, being made temporarily smarter may compel the continued pursuit of artificial enhancement of mental capabilities even at disproportionate expense. Even without sideeffects, the compulsion to sustain a drugenhanced mental state may itself be a negative effect. If 'smart drugs' are once made available and prove effective, the demand for them will be intensive and require their continued supply. Even forcible removal of access to such treatments, by prohibiting their distribution or use, is unlikely to prove effective: a black market in psychotropic drugs already flourishes, and extending this to neurotropic drugs would scarcely be difficult.

Precaution alone, however, is an insufficient reason to declare such treatments unethical. Even something as potentially seductive as increased brain function should not be prohibited on the basis of some paternalistic urge to protect the populace from itself. Indeed, since increasing brain function may well be beneficial both to the individual and society, there are powerful reasons to pursue these possibilities rather than to ban them.

Additionally, if such treatments are available legitimately as therapy, it may be problematic to distinguish the cases to which therapeutic treatment ought to be permissible, and to ensure the use of treatments is restricted solely to these.
Already, students seeking ways to improve their academic performance are using Ritalin to promote alertness and reduce the need for sleep. Although the drug is restricted to prescription use for AD H D treatment, students may attempt to present a false diagnosis in order to obtain a prescription; or they may buy it (illegally) from others with a genuine prescription or with an illegitimate source of supply.

This is a frequently raised issue regarding enhancement in general: whether we ought to support or allow enhancing treatments for al ready healthy, or in this case mentally normal, individuals. Treatments conferring a level of function above the norm, it is suggested, are morally different and somehow less permissible than therapeutic interventions that are aimed at restoring 'normal' function. However (as has been argued extensively elsewhere [19]), the concept of normalcy in terms of what is 'speciestypical' is redundant in a world that already incorporates modern medical technology to transcend the limits of 'natural' health; therefore the distinction between therapy and enhancement is blurred at best and at worst nonexistent. This is particularly applicable to mental capacity, where the range and definition of what is normal is so broad and complex as to render almost any alteration explicable as either therapy or enhancement. H ow severe must a condition be before we allow treatment to be administered, and how can such a distinction be justified? Is treatment for a child who has been classified clinically as suffering from ADHD somehow more morally acceptable than the same treatment for a child with a short attention span who has not received a clinical diagnosis? And is there a step change from these two cases to a scenario in which an individual simply wants to get the most out of school or university by taking drugs that will aid concentration and retention of what has been learnt?

A fundamental question is then whether there is something wrong with improving upon nature or upon normal functioning or species typical functioning.

Consider the use of spectacles (I first used this analogy at a public meeting in Cheltenham Town $\mathrm{H}$ all on 18th November 2005. Steven Rose has recently used the same idea [20]). Spectacles are an enhancement technology albeit one designed to restore sight to what constitutes normal functioning or to repair or correct disease, damage or injury. This idea defines health and hence illness in terms of departures 
from normal functioning or departures from species typical functioning along lines developed by Boorse and D aniels [21,22].

$\mathrm{N}$ ow consider the use of a telescope or binoculars or a microscope. These tools are not used to restore normalcy or treat disease or injury. They are done to enhance powers and capacities.

It is interesting to speculate as to how many of those who have ever used binoculars thought they were crossing a moral divide when they did so. H ow many scientists who use a microscope or race-goers who take their binoculars with them, thought that they were crossing some moral Rubicon?

Some people think that whether or not the enhancement is mechanical or chemical makes a moral difference. $0 \mathrm{n}$ this view bicycles are acceptable but steroids not. Steven Rose for example makes this point forcefully. $\mathrm{H}$ aving used substantially the same contrast as I have made between spectacles and telescopes he goes on to say:

"It is true that when Galileo developed the tele scope there were those among his compatriots who refused to look through it, but few today would share this ethical discomfort. Yet in the context of substances that interact directly with our bodily biochemistry, we feel a considerable unease, reflected in custom and law. It is alright to change our body chemistry by training, but to achievea similar effect with steroids is illegal for athletes. It is alright to buy educational privilege for onés children by paying for privatetuition, but dubious to enhance their skills by feeding them drugs."

If we search in this passage (or elsewhere in Rose's essay) for a rational defence of this difference we find only an appeal to custom and law or to the 'yuck factor'. "We feel" he says "a considerable unease reflected in custom and law', and yet this same unease was felt by $G$ alileo's compatriots with the same degree of justification!"

Imagine a wonderful futuristic scenario in which we could eliminate infectious diseases by the use of effective vaccines. Presumably we would welcome this as a wonderful and effective public health measure, which saved lives, saved money, and minimized suffering and distress. Vaccination is of course an enhancement technology and one that has been long accepted (since small pox vaccine was first used in the middle of the 18th Century).

Since vulnerability to smallpox and polio, or to measles, mumps and rubella is perfectly normal and natural then, if we alter human beings to affect their vulnerability to these things we are enhancing them. We are interfering with perfectly normal and perfectly healthy human beings (babies or adults) to enhance them.

The core of the problem is whether or not there is a difference between a disability and an inability from the point of view of the legitimacy of altering that state. $\mathrm{H}$ ealthy individuals are not disabled even if they have not been vaccinated, but they have an inability to resist, for example, polio. Equally healthy individuals may be unable to concentrate for long periods or manage on very little sleep or retain in their memory most of what they have learnt. If drugs or other procedures can alter this for the better are there moral or for that matter social reasons to draw a distinction?

If neuro-enhancement benefits the individual then it follows that providing enhancement is doing good. M orality usually encourages us to do good to others if we can and certainly enjoins us not to deny others the chance of benefiting themselves.

In the context of society as a whole, however, is it good to make available a procedure that might enable some to advantage themselves or their children at the expense of others? This is a complicated question and one which cannot be adequately addressed here. We should note however that it does not follow from the fact (if it is a fact) that something is undesirable that it should not be permitted or tolerated.

Consider again Steven Rose's suggestion that: "It is alright to buy educational privilege for one's children by paying for private tuition, but dubious to enhance their skills by feeding them drugs." Rose implies that it is indeed dubious. For our part we see no relevant distinction here. Firstly Rose has misdescribed the issue. Parents who pay for private tuition or send their children to expensive schools may be buying educational privilege, but they are also doing what any good parent should do - ensuring that their child has the best possible education. Arguably making drugs available (assuming them to be safe) that will also enhance their children's education is equally good or at least, in Rose's words, 'alright'.

It may not be the most urgent use of public resources to increase the intelligence of healthy, already mentally capable individuals; but this does not preclude making such treatments available on a privately-funded basis. $\mathrm{H}$ owever, if the weal thy receive greater access to neuro-enhancement treatments because of their ability to pay, will the presumed consequent increase in this group's abilities lead to a widening of the social 
divide between the rich and the poor? Rather than an argument for restricting neuro-enhancing treatments and denying society the benefits that could result, this should be a reason to ensure that such benefits are made as widely available as possible.

Is there, then, anything to be feared in our growing understanding of human brain function and the abilities we might potentially acquire to modify and improve human mental capacity? 0 ne can envision a world in which children are given the best possible genetic opportunities for developing the unique human resource of their minds and where intellectual performance is routinely boosted by pharmacological or computer-based technologies, assisting people to greater fulfilment of their potential in all areas of life. It might be argued that a society in which neuroenhancement is routinely available will force everyone to utilize enhancement technologies in order to be competitive. However, if neuroenhancement is of benefit, it may well be desirable to encourage its use. We already accept the society-wide use of other beneficial interventions, from fluoridation of drinking water to the wearing of seatbelts in motor vehicles; and the use of drugs such as aspirin and statins is approaching universality for those at risk of heart disease (which is virtually the whole population over a certain age). There is a sense in which if people want to avoid premature death they are forced to take drugs like statins and aspirin or give up unhealthy foods and take exercise in order to 'compete'.

There are many enhancement strategies that humans have developed which are costly and seem to threaten to increase inequalities between rich and poor, creating a race for advantage which threatens to leave some behind and make elites of others. Writing was probably one such 'technology', with the liter- ate, having access to books, one such elite. Books and writing materials were expensive and learning to read costly in terms of time, effort and other resources. Then came universities and schools: the cost of universal school education is enormous and the costs of access to higher education for all capable of benefiting from it are also massive. Again these enhancing strategies threatened to create elites and start an education race, which in a sense they did. M ore recently access to computers and to the internet have raised similar issues and concerns. $\mathrm{H}$ owever the solution was perceived to be to strive for universal access to such life enhancing strategies and technologies. The same was true, as we have noted, with vaccines and with spectacles. These too threatened to create elites of advantaged individuals. We have attempted to achieve universal access to polio vaccine and others and before it to smallpox vaccine. Access to spectacles is widespread if not universal.

The challenge is of course to understand which races are worth running and which strategies are worth adopting. It may be that some of the new enhancing strategies whether from regenerative medicine or from chemical enhancers will prove not to be worth it. Or if they are of value, perhaps the inequalities they threaten will prove more intractable than others. We don't know the answer to either of these questions. H owever two things seem clear. The first is that it is doubtful that there are cogent ethical objections to human enhancement per se. Second, the right approach to inequalities created by science and technology, whether these are access to education or organ transplants [23], to drugs, vaccines or spectacles, or to medical technologies to improve or enhance brain function, seems to be to attempt to 'level up' rather than to deny advantages to some unless and until they can be provided to all.
Bibliography

1. Aristotle ED. D e partibus animalium. Revised edition. H arvard U niversity Press, London, UK (1961).

2. Correia AS, Anisimov SV, Li JY, Brundin P: Stem cell-based therapy for Parkinson's disease. Ann. M ed. 37, 487-498 (2005).

3. $\mathrm{H}$ elmchen $\mathrm{H}$ : Forthcoming ethical issues in biological psychiatry. World J. Biol.

Psychiatry 6(Suppl. 2), 56-64 (2005)

4. Turnpenny L, Cameron IT, Spalluto CM , $\mathrm{H}$ anley KP, W ilson DI, $\mathrm{H}$ anley $\mathrm{N} A$ : $H$ uman embryonic germ cells for future neuronal replacement therapy. Brain Res. Bull 68, 76-82 (2005).

5. Austin J: Schizophrenia: an update and review. J. Genet. Couns. 14, 329-340 (2005).

6. Biederman J: Attention-deficit/hyperactivity disorder: a selective overview. Biol. Psychiatry 57, 1215-1220 (2005).

7. Baldwin T: Behavioural genetics: prospects and challenges. H um. Fertil. (Camb) 7 , 11-18 (2004).
8. Skuse D H : X-linked genes and mental functioning. H um. M ol. Genet. 14(Spec. N 0. 1), R27-R32 (2005).

9. Baharloo S, Service SK, Risch N, Gitschier J, Freimer N B: Familial aggregation of absolute pitch. Am. J. H um. Genet. 67, 755- 758 (2000).

10. Tang YP, Shimizu E, Dube GR et al.: $G$ enetic enhancement of learning and memory in mice. N ature 401, 63-69 (1999). 
11. M aguire Jr GQ, M cGee EM : Implantable brain chips? Time for debate. $\mathrm{H}$ astings $\mathrm{C}$ ent. Rep. 29, 7-13 (1999).

12. Gottfredson LS: Intelligence: is it the epidemiologists' elusive 'fundamental cause' of social class inequalities in health? J. Pers. Soc. Psychol. 86, 174-199 (2004).

13. D eary IJ, Batty D, Gottfredson LS: H uman hierarchies, health, and IQ. Science 309, 703; author reply 703 (2005).

14. Rose SP: 'Smart drugs': do they work? Are they ethical? W ill they be legal? $\mathrm{N}$ at. Rev. N eurosci. 3, 975-979 (2002).

15. Turner D C, Clark L, Pomarol-Clotet E, M cK enna P, Robbins T W, Sahakian BJ: Modafinil improves cognition and attentional set shifting in patients with chronic schizophrenia. N europsychopharmacology 29, 1363-1373 (2004).
16. Turner DC, Clark L, D owson J, Robbins TW, Sahakian BJ: M odafinil improves cognition and response inhibition in adult attention-deficit/hyperactivity disorder. Biol. Psychiatry 55, 1031-1040 (2004).

17. Turner DC, Robbins TW, Clark L, Aron AR, D owson J, Sahakian BJ : Cognitive enhancing effects of modafinil in healthy volunteers. Psychopharmacology (Berl) 165, 260-269 (2003).

18. N uffield C ouncil on Bioethics. The use of primates in research. London, UK (2006).

19. Chan $\mathrm{S}, \mathrm{H}$ arris ] : In support of enhancement. Theoretical M edicine and Bioethics (In Press) (2006).

20. Rose SP: Brain Gain? In: From smart pills to designer babies and extended lifespans, technology now promises to transform our very nature. Better H umans. M iller $\mathrm{P}$, W ilson J (Eds). D emos, London, UK (2006).
21. D aniels $\mathrm{N}$ : Justice and Justification. Cambridge University Press, Cambridge, UK (1996).

22. Boorse $\mathrm{C}: \mathrm{O} \mathrm{n}$ the distinction between disease and illness. Philosophy and Public Affairs 5, 49-68 (1975).

23. H arris J. Intimations of Immortality - The Ethics and Justice of Life Extending Therapies. In: Current Legal Problems, Freeman M (Ed.), O xford University Press, O xford, U K (2002). 